\title{
Training in Highland Vegetable Cultivation Using Verticulture Method in The Arafah Permai Housing in Koto Panjang Town, Padang Panjang
}

\author{
Indra Hartanto ${ }^{1 *}$, Resti Fevria ${ }^{1}$, Vauzia $^{1}$ \\ 1 Department of Biology, Faculty of Mathematics and Natural Sciences, Universitas Negeri Padang, Indonesia \\ * Correspondence: indrahartanto1971@gmail.com; Tel.: +62-822-858-32864
}

Diterima 19 November, Disetujui 24 November Dipublikasikan 30 November 2018

\begin{abstract}
The increasing number of human populations will certainly reduse the amount of productive land, especially in urban areas. Food consumption needs that continue to increase but not offset by production will certainly threaten human survival. The narrower of productive land especially in urban areas certanly requires a way to maximize the limited use of land in order to remain productive, one of which is the cultination of plants with a verticulture system. Padang Panjang city include highland temperate rigion, therefore many vegetable can grow and develop in this area like cale, pakcoy and lettuce. No exeption for Arafah Permai housing which is located in Padang Panjang city with a farm/ narrow yard that is suitable for cultivation systems using this verticulture method.
\end{abstract}

Key words: highland vegetables, verticulture method, Padang Panjang City.

\section{Pendahuluan}

Peningkatan pertumbuhan jumlah penduduk dari tahun ke tahun menimbul negatif, salah satunya peningkatan alih fungsi lahan pertanian menjadi lahan pemukiman (Wartapa dkk, 2010). Semakin meningkatnya jumlah populasi manusia tentunya akan mengurangi jumlah lahan produktif khususnya didaerah perkotaan. Kebutuhan konsumsi pangan yang terus meningkat namun tidak diimbangi dengan produksi tentunya akan mengancam kelangsungan hidup manusia. Semakin sempitnya lahan produktif khususnya didaerah perkotaan tentu menuntut adanya suatu cara untuk memaksimalkan pemanfaatan lahan terbatas tersebut agar tetap produktif, salah satunya budidaya tanaman dengan sistem vertikultur (Hartanto dkk, 2018).

Vertikultur adalah cara bertanam dalam susunan vertikal keatas menuju ruang udara bebas, dengan susunan media tanam yang juga disusun secara vertikal. Cara tanam ini sesuai diterapkan pada pekarangan dengan lahan terbatas, lahan sempit, bahkan lahan sedikitpun (BPTP, 2006). Media tanam adalah komponen utama dalam menunjang pertumbuhan tanaman. Bagi tanaman, media tanam memiliki banyak peran seperti sebagai tempat bertumpu agar tanaman tetap tumbuh tegak, yang didalamnya terkandung air, hara dan udara yang diperlukan oleh tanaman, selain itu media tanam juga berfungsi untuk menjaga kelembaban daerah disekitar akar, penyedia udara yang cukup dan dapat menahan ketersediaan unsur hara. Untuk itu diperlukan media tanam yang sesuai untuk diterapkan dalam teknik vertikultur. Media tanam vertikulutur dengan hasil terbaik adalah $50 \%$ tanah : 50\% kompos di Kota Padang Panjang (Hartanto, 2018). Media tanam dapat ditampung dalam paralon pvc. Bentuk atau susunan vertikultur tentunya harus disesuaikan dalam teknik vertikultur adalah tanaman sayuran semusim dengan tinggi maksimal satu (1) meter. Sayuran yang cocok ditanam dengan sistem vertikultur ini diantaranya adalah kale, pakcoy dan selada.

Kale (Brasicca olearaceae) merupakan tanaman semusim dengan umur panen 40-50 hari. Kale memiliki banyak nutrisi dan mempunyai nilai ekonomi tinggi, begitu juga dengan pakcoy (Brasicca rapa L) merupakan sayuran daun 
dengan nilai ekonomi tinggi, juga dapat tumbuh didaerah dataran tinggi. Selada (Lactuca sativa $L$ ) adalah tanaman yang termasuk dalam famili compositae. Sebagian besar selada dimakan dalam keadaan mentah. Selada merupakan sayuran yang populer karena memiliki warna, tekstur serta aroma yang dapat menyegarkan tampilan makanan. Tanaman ini merupakan tanaman setahun yang dapat dibudidayakan didaerah lembab, dingin, dataran rendah maupun dataran tinggi. Pada dataran tinggi yang beriklim lembab produktivitas selada cukup baik.

Kota Padang Panjang termasuk daerah dataran tinggi yang beriklim lembab, oleh sebab itu banyak sayuran dapat tumbuh dan berkembang dengan baik didaerah ini. Semua kondisi yang disampaikan sebelumnya, sangat cocok dengan keadaan di Perumahan Arafah Permai Kota Padang Panjang. Dimana perumahan ini terletak didaerah perkotaan dengan lahan pertanian/ halaman yang sempit dan berada didaerah dataran tinggi yang beriklim lembab.

\section{Solusi/ Teknologi}

\section{A. Solusi}

Tujuan PKM Pelatihan Budidaya Sayuran Dataran Tinggi dengan Metode Vertikultur di Perumahan Arafah Permai Kelurahan Koto Panjang Kota Padang Panjang dapat dicapai dengan cara :

1. Pelatihan Budidaya Sayuran Dataran Tinggi dengan Metode Vertikultur secara vertikal bagi ibu-ibu PKK dan dasawisma di Perumahan Arafah Permai, sehingga dapat memiliki nilai ekonomi bagi masyarakat.

2. Menggunakan wadah yang mudah didapat atau wadah yang tahan lama seperti bambu dan pipa paralon pvc, dengan media utama tanah dan kompos.

3. Mensinergikan kegiatan-kegiatan yang akan dilaksanakan pada pengabdian ini dengan agenda yang ada pada kegiatan ibu-ibu PKK dan dasawisma seperti kegiatan arisan dan jadwal pertemuan rutin bulanan RT 16.

\section{B. Metode Pelaksanaan}

Transfer IPTEK yang dilakukan pada tiap tahapnya menggunakan prinsip bahwa setiap inovasi yang diterima oleh mitra sebaiknya melalui proses mendengar, mengetahui, mencoba, mengevaluasi, menerima, meyakini dan melaksanakan. Melalui proses-proses tersebut diharapkan keterampilan yang diberikan dapat diadopsi secara berkesinambungan dan mandiri kedepannya. Supaya setiap proses berlangsung dengan baik, maka penyampaian keterampilan kepada Mitra ditempuh melalui tahapan penjelasan, diskusi, praktek serta dilakukan tahap pendampingan. Secara umum proses pendekatan untuk membantu mitra pada kegiatan ini adalah sebagai berikut :

1. Sosilalisasi Program, meskipun mitra sudah bersedia untuk bekerjasama, sosialisasi perlu juga dilakukan untuk melibatkan masyarakat lebih luas.

2. Rencana Tindakan, rincian aktivitas pembinaan perlu disampaikan secara detail, karena setiap langkah pembinaan membutuhkan partisipasi mitra.

3. Penyusunan Rencana Kegiatan, kegiatan ini dilakukan dengan memberikan materi tentang Metode Vertikultur, media yang digunakan serta bahan yang digunakan. Materi apa yang dimaksud dengan metode vertikultur, kelebihan dan kekurangan vertikultur serta tekhnik pelaksanaannya ; yang dimulai dari penyiapan bahan, pembuatan media tanam, penentuan jenis sayuran yang akan ditanam, penyemaian, pembibitan, penanaman, pemeliharaan serta evaluasi. Wadah yang digunakan adalah paralon pvc yang lebih tahan lama dengan media tanam tanah $50 \%$ dan kompos $50 \%$.

4. Program Pemeliharaan, program pemeliharaan dirancang dengan baik, dengan melakukan evaluasi secara periodik kelapangan. Hal ini bertujuan untuk membantu jika dalam pelaksanaan secara mandiri terdapat kendala.

5. Rancangan Evaluasi, untuk melihat keterlaksanaan dan ketercapain target yang diharapkan maka diakhir kegiatan disebarkan angket yang berisi pertanyaan- 
pertanyaan tentang kegiatan yang telah dilakukan.

\section{Hasil dan Diskusi}

\section{A. Teknologi Budidaya Tanaman Sayuran Secara Vertikultur.}

Vertikultur berasal dari bahasa Inggris, yaitu vertical atau culture, maka vertikultur adalah sistem budidaya pertanian yang dilakukan secara vertikal atau bertingkat. Sistem budidaya pertanian secara vertikal atau bertingkat ini merupakan konsep penghijauan yang cocok untuk daerah perkotaan dan lahan terbatas, dapat dilihat pada gambar 1 .

Vertikultur tidak hanya sekadar kebun vertikal, namun ide ini akan merangsang seseorang untuk menciptakan khasanah biodiversitas di pekarangan yang sempit sekalipun. Pertanian vertikultur tidak hanya sebagai sumber pangan tetapi juga menciptakan suasana alami yang menyenangkan.

\section{B. Pembuatan Wadah Tanam Vertikultur}

Wadah dibuat
menggunakan pipa paralon pve dengan
ukuran 10 inch. Kemudian paralon
dilubangi secara spiral dengan diameter
$10 \mathrm{~cm}$ dengan menggunakan bor listrik.
Wadah vertikultur ini dapat dilihat pada
gambar 2 .

\section{Pengadaan Media Tanam}

Media tanam adalah tempat tumbuhnya tanaman untuk menunjang perakaran. Dari media tanam inilah tanaman menyerap makanan berupa unsur hara melalui akarnya. Media tanam yang digunakan adalah campuran tanah 50\% dan pupuk kandang $50 \%$. Setelah semua bahan terkumpul, dilakukan pencampuran hingga merata. Tanah dengan sifat koloidnya memiliki kemampuan untuk mengikat unsur hara, dan melalui unsur hara dapat diserap oleh akar tanaman dengan prinsip pertukaran kation. Campuran media tanam kemudian dimasukkan kedalam paralon hingga penuh. Untuk memastikan tidak ada ruang kosong, dapat digunakan bambu kecil atau kayu untuk mendorong tanah hingga kedasar wadah. Media tanam didalam paralon diusahakan agar tidak terlalu padat supaya air mudah mengalir, juga supaya akar tanaman tidak kesulitan bernafas dan tidak terlalu renggang agar ada keleuasaan dalam mempertahankan air dan menjaga kelembaban seperti pada gambar 3 .

\section{Persiapan Bibit Tanaman dan Penanaman}

Sebelum membuat wadah vertikal, terlebih dahulu dipersiapkan sejumlah bibit tanaman sampai tanaman mencapai umur siap dipindahkan. Ada tiga tahap dalam proses ini yaitu, persemaian, pemindahan dan penanaman. Seperti halnya menanam, menyemaikan benih juga memerlukan wadah dan media tanam. Wadah bisa apa saja sepanjang dapat diisi media tanam seperlunya dan memiliki lubang dibagian bawah untuk mengeluarkan kelebihan air, seperti pot ukuran sedang atau kotak bekas tempat kue. Untuk media tanamnya adalah media dari produk jadi yang bersifat organik. Seperti gambar 4.

Jumlah benih yang dapat disemaikan sudah terukur karena setiap lubang diisi satu benih. $5-8$ hari setelah persemaian, benih sudah berkecambah dan mengeluarkan 3-4 daun. Idealnya, benih yang sudah tumbuh daun berjumlah $4-5$ helai sudah layak dipindahtanamkan.

Bibit tanaman yang dipindahkan ke wadah vertikultur sudah berumur lebih dari satu bulan, daunnya pun sudah bertambah. Sebelum bibit-bibit ditanam diwadah, terlebih dahulu menyiramkan air kedalamnya hingga jenuh, yang ditandai dengan menetesnya air keluar dari lubanglubang tanam. Setelah cukup, baru mulai 
menanam bibit satu demi satu. Semua bagian akar dari setiap bibit harus masuk kedalam tanah. Setiap jenis bibit ( Kale, Pakcoy dan selada) dikelompokkan diwadah yang terpisah. Seperti terlihat pada gambar 5 .

\section{E. Pemeliharaan Tanaman}

Tanaman juga memerlukan perawatan, seperti halnya makhluk hidup yang lain. Tanaman memerlukan perhatian dan kasih sayang. Selain penyiraman dilakukan setiap hari juga perlu pemupukan, dan pengendalian hama. Sebaiknya pupuk yang digunakan adalah pupuk organik. Limbah dapur atau daun-daun kering bisa dimanfaatkan untuk pembuatan pupuk bokashi.

Saat ini masyarakat mulai banyak mempertimbangkan mengkonsumsi hasil panen yang lebih sehat cara penanamannya, yaitu menggunakan pupuk dan pengendalian hama alami, meskipun harga produk tersebut lebih mahal. Saran untuk berkebun dirumah sebaiknya tidak menggunakan bahan kimia.

\section{F. Pemanenan}

Pemanenan sayuran biasanya dilakukan dengan sistem cabut akar ( selada, pakcoy). Apabila kita punya tanaman sendiri dan dikonsumsi sendiri akan lebih menghemat apabila panen dilakukan dengan mengambil daunnya saja. Dengan cara tersebut tanaman sayuran bisa bertahan lebih lama dan bisa panen berulang-ulang. Seperti pada gambar 6.

\section{Kesimpulan}

Budidaya sayuran secara vertikultur sangat dianjurkan untuk perumahan yang berada diperkotaan, karena sistem vertikultur ini sangat disarankan untuk lokasi lahan pertanian terbatas dan sempit.
Budidaya secara vertikultur ini dapat dilakukan dalam beberapa tahap yaitu, penyiapan wadah dan media tanam, pembibitan, penanaman dan pemeliharaan serta pemanenan.

\section{Ucapan Terima Kasih}

Ucapan terima kasih disampaikan kepada semua pihak yang telah membantu terlaksananya PKM ini yaitu Dekan FMIPA UNP dan Jajarannya, Ketua Jurusan Biologi dan Jajarannya, Ketua LP2M dan Jajarannya, mitra PKM Ketua RT 16 Perumahan Arafah Permai Padang Reno, Ibu-ibu PKK dan Dasawisma Perumahan Arafah Permai Padang Reno dan lainlain yang telah membantu pelaksanaan PKM ini.

\section{Pustaka}

[1] BPTP, 2006; Mulatsih dkk, 2005, Kawasan Rumah Pangan Lestari, Budidaya sistem vertikultur, Sumatera Barat.

[2] Hartanto, Indra, 2018. Analisa Pertumbuhan Sayuran Dataran Tinggi dengan Metode Vertikultur di Kota Padang Panjang. Jurusan Biologi FMIPA UNP

[3] Mulyono, 2014. Budidaya Sistem Pertanian Vertikal (Vertikultur). Fakultas Pertanian UGM Bulak Sumur. Yogyakarta.

[4] Lukman, Liferdi, 2015. Teknologi Budidaya Tanaman Sayuran Secara Vertikultur. Balai Penelitian Tanaman Sayuran. Lembang Bandung.

[5] Padang Panjang Dalam Angka, 2015. Luas Lahan Pertanian di Kota Padang Panjang. Bappeda-BPS Kota Padang Panjang.

[6] Sompotan, 2013. Hasil Tanaman Sawi (Brassica Juncea L.) Terhadap Pemupukan Organik dan An Organik. Jurnal Geosains Vol. 2 No.1 hal : 14-17. Jurusan Budidaya Pertanian, Fakultas Pertanian Universitas Sam Ratulangi, Manado.

[7] Wartapa A,S.Sugihartiningsih, S.Astuti, dan Sukadi.2010. Pengaruh Jenis Pupuk 
dan Tanaman Antagonis Terhadap Hasil

Cabai Rawit (Capsicum frutencens) Budidaya Vertikultur. Ilmu-Ilmu Pertanian, 6(2):152-156
[8] Yenisbar, Wayan Raniwiwati, 2012. Pertanian Perkotaan Dengan Sistem Vertikultur

Gambar 1.Gambar budi daya tanaman secara vertikultur

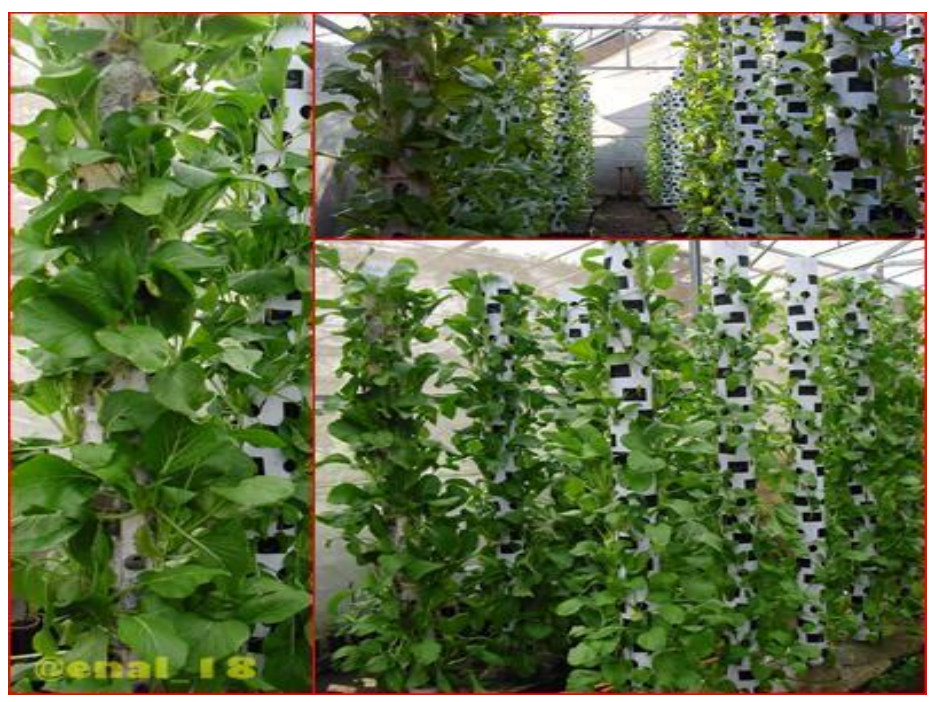

Gambar 2.Wadahvertikultur

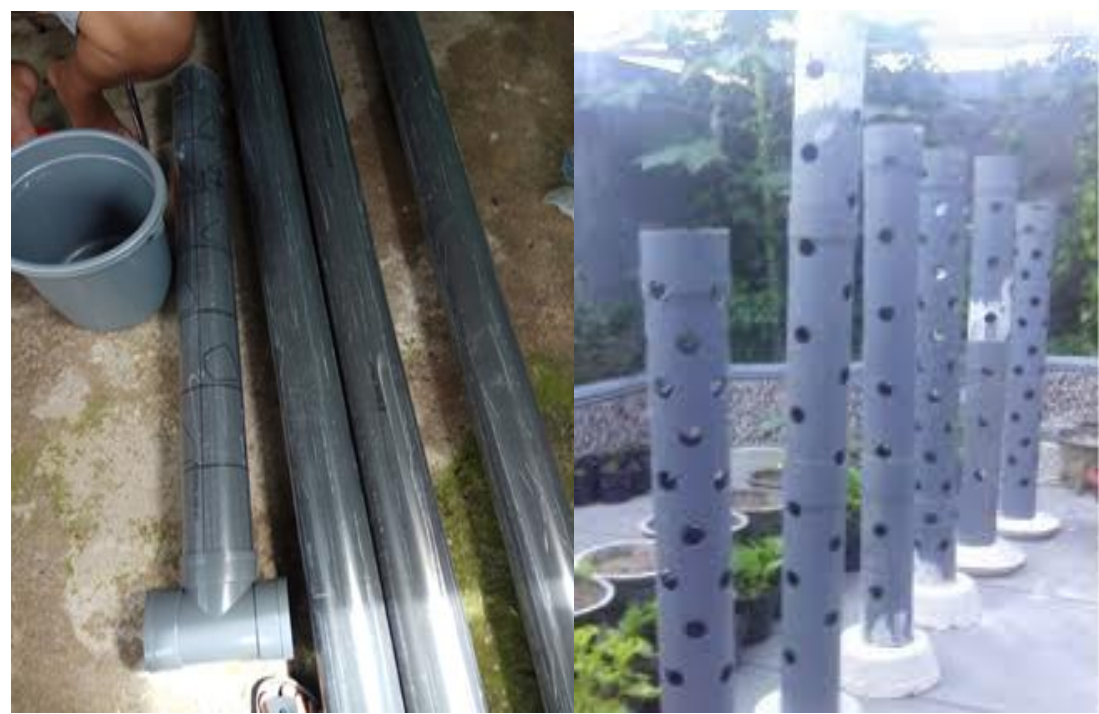


Gambar 3. Media Tanam

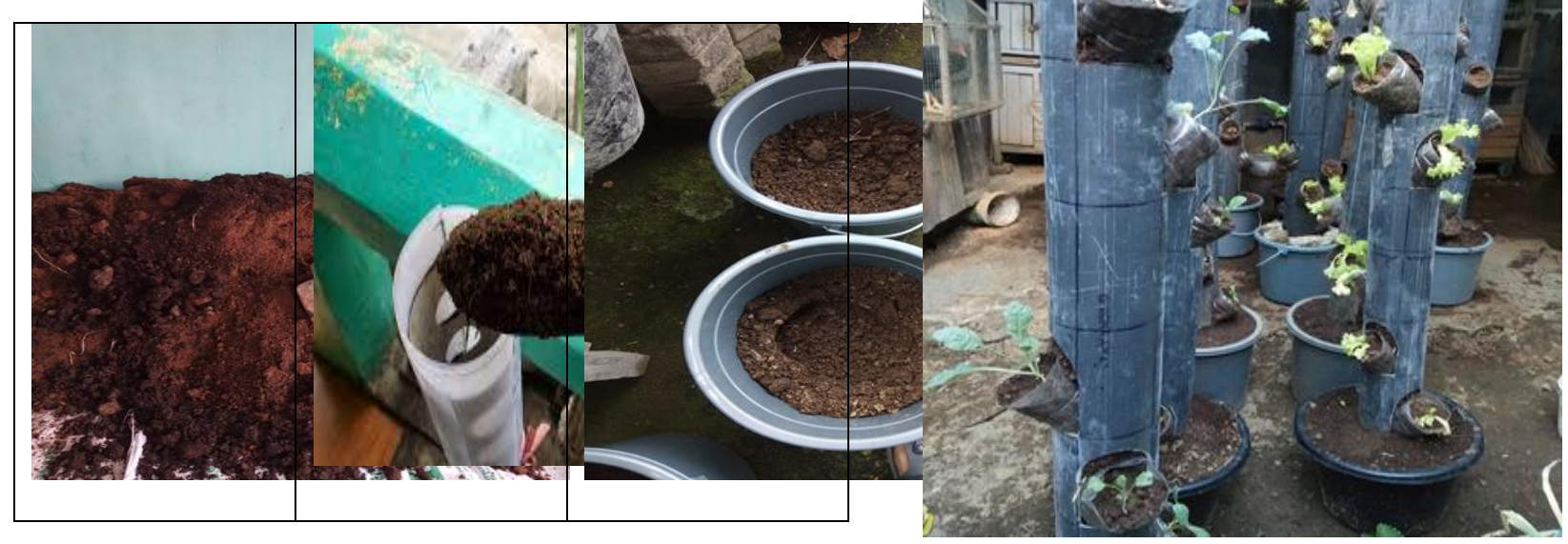

Gambar 4.Benihsayuran yang siapdipindahkanke

Gambar 6.Pemanenan.

media tanam

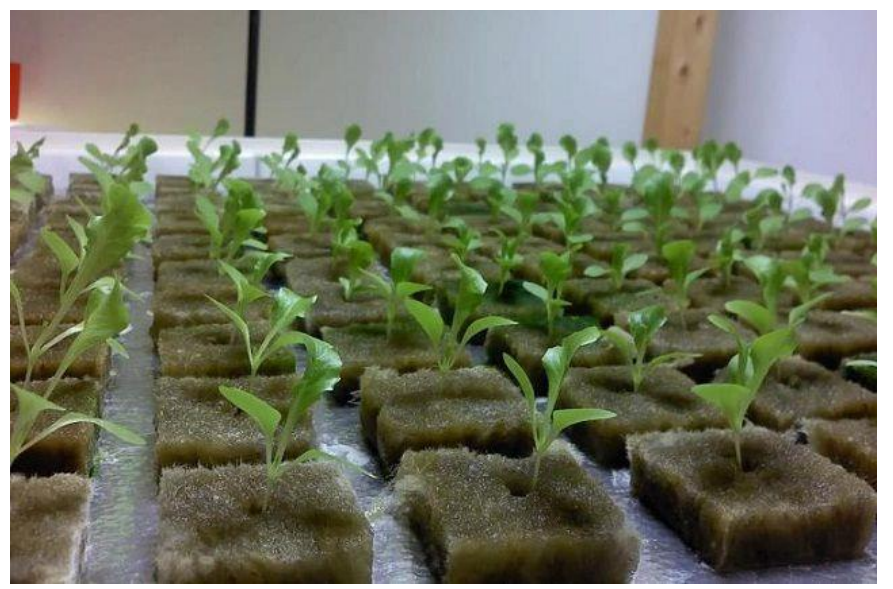

Gambar 5.Penanaman

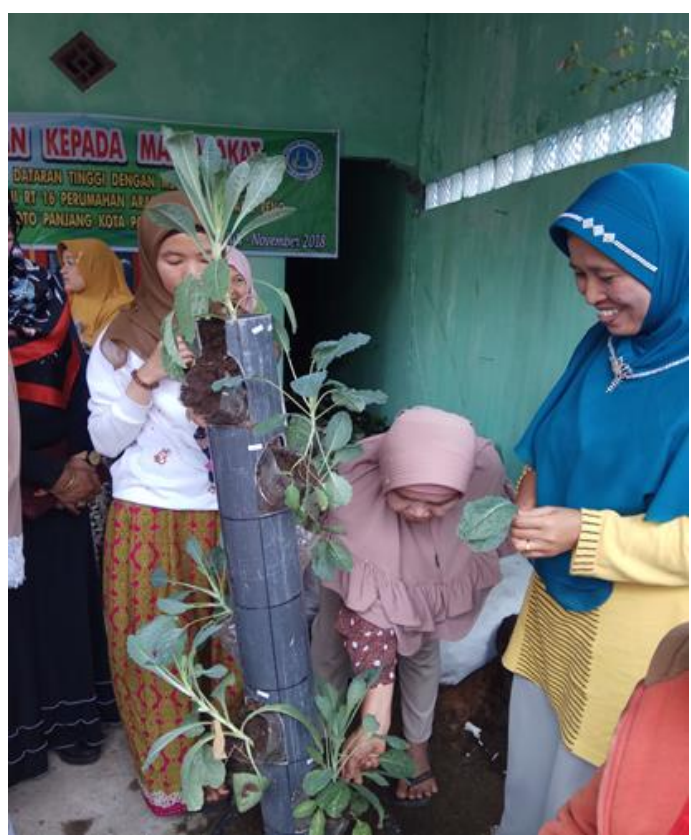

